\title{
ASYMPTOTIC BEHAVIOR OF INTERMEDIATE POINTS IN CERTAIN MEAN VALUE THEOREMS
}

\author{
TIBERIU TRIF
}

Abstract. The paper deals with asymptotic behavior of intermediate points in certain mean value theorems: the Cauchy-Taylor mean value theorem, a generalization due to I. Pawlikowska of Flett's mean value theorem, and a Cauchy version of Pawlikowska's mean value theorem.

Mathematics subject classification (2000): 26A24, 41A60, 41A80.

Key words and phrases: Mean value theorems, asymptotic approximations, asymptotic expansions.

\section{REFERENCES}

[1] U. ABEL, On the Lagrange remainder of the Taylor formula, Amer. Math. Monthly, 110 (2003), 627-633.

[2] U. ABEL AND M. IVAN, The differential mean value of divided differences, J. Math. Anal. Appl. 325 (2007), 560-570.

[3] U. ABEL, M. IVAN AND T. RIEDEL, The mean value theorem of Flett and divided differences, J. Math. Anal. Appl. 295 (2004), 1-9.

[4] A. G. AZPEITIA, On the Lagrange remainder of the Taylor formula, Amer. Math. Monthly 89 (1982), 311-312.

[5] L. COMTET, Advanced Combinatorics, Reidel, Dordrecht, 1974.

[6] D. I. DUCA AND O. POP, On the intermediate point in Cauchy's mean-value theorem, Math. Inequal. Appl. 9 (2006), 375-389.

[7] T. M. FLETT, A mean value theorem, Math. Gazette 42 (1958), 38-39.

[8] I. PAWLIKOWSKA, An extension of a theorem of Flett, Demonstratio Math. 32 (1999), 281-286.

[9] R. C. Powers, T. Riedel AND P. K. SAHOO, Limit properties of differential mean values, J. Math. Anal. Appl. 227 (1998), 216-226.

[10] P. K. SAHOO AND T. RIEDEL, Mean Value Theorems and Functional Equations, World Scientific, River Edge, NJ, 1998. 